\title{
A Green One-Pot Synthesis of Benzochromeno-Pyrazoles Catalyzed by a Series of Metal Triflates
}

\author{
SAMAN DAMAVANDI
}

Department of Chemistry, Islamic Azad University, Sarvestan Branch, Sarvestan, Iran saman_damavandi@yahoo.com

Received 7 May 2012 / Accepted 18 May 2012

Abstract: A series of triflate salts have been examined for synthesis of benzochromeno-pyrazole derivatives from three component one-pot reaction of aromatic aldehydes, 3-methyl- $1 \mathrm{H}$-pyrazol5(4H)-one and $\alpha$-or $\beta$-naphthol under solvent-free conditions.

Keywords: Benzochromeno-pyrazole, Green synthesis, Multicomponent reaction

\section{Introduction}

Multi-component condensations (MCRs) constitute an especially attractive synthesis strategy for rapid and efficient generation of products due to the fact that the products are formed in a single step and also the diversity could be achieved simply by varying the reacting components ${ }^{1}$.

During the past few years, the outstanding potential of a variety of metal triflates has been discovered, thus triggering much research endeavour. The triflate anion is both weakly nucleophilic and coordinating, rendering the metal counter ion more cationic and thus a stronger Lewis acid ${ }^{2}$. Although metal triflates have long been known to promote elimination reactions, oxidative coupling reactions and reactions of diazo compounds ${ }^{3}$ but its full synthetic capacity has long remained unveiled. In general, Lewis acid catalyzed reactions have gained increasing interest due to the unique reactivity and selectivity that can be achieved under mild conditions.

Chromene compounds occupy an important place in the realm of natural and synthetic organic chemistry. They are used as anticoagulants, additives in food and cosmetics, and in the preparation of insecticides, optical brighteners, and dispersed fluorescent and laser dyes ${ }^{4}$. Chromenopyrazoles are known to exhibit interesting biological properties ${ }^{5}$. Some procedure for synthesis of chromeno-pyrazole derivatives have been reported already: Abunada et al. ${ }^{6}$ studied synthesis of chromeno[3,4-c]pyrazole derivatives from hydrazonoyl bromides and substituted coumarins. Heravi et al. $^{7}$ reported one-pot synthesis of benzochromenopyrazoles catalyzed by sulfamic acid.

Nowadays there is an increasing awareness of urgent necessity to limit, as far as possible, any source of pollution. Facing up to these facts, chemists have to dedicate numerous efforts to the development of clean technologies ${ }^{8}$. This new challenge has led to growing interest in the displacement of organic reaction in aqueous media ${ }^{9}$ and solvent free conditions ${ }^{10,11}$. 
To continue our work in the synthesis of heterocyclic compounds via MCR reactions ${ }^{12,13}$, herein, we wish to report an efficient and green synthetic route to chromenopyrazole derivatives via one-pot three component condensation of aldehydes, 3-methyl- $1 \mathrm{H}$ pyrazol-5(4H)-one and $\alpha$-or $\beta$-naphthol catalyzed by a series of metal triflates (Scheme 1 ).

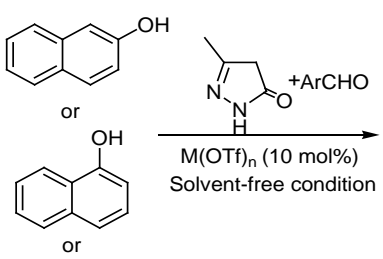

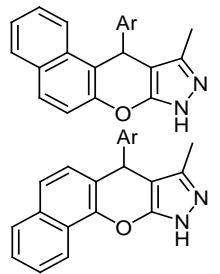

Scheme 1. One-pot synthetic route to benzochromeno-pyrazole derivatives

\section{Experimental}

A mixture of an aromatic aldehyde ( $1 \mathrm{mmol})$, 3-methyl- $1 H$-pyrazol-5(4H)-one (1 mmol) and $\alpha$-or $\beta$-naphthol ( $1 \mathrm{mmol})$, in the presence of cupper(II) triflate $(10 \mathrm{~mol} \%)$ was triturated together and the reaction mixture was heated at $80{ }^{\circ} \mathrm{C}$ for a certain time (monitored by TLC). Upon completion of the reaction, the reaction mixture was allowed to cool to room temperature, washed with water and recrystallized from absolute ethanol to give the pure products. Characterizations of selected products are as follows:

(Entry 3): mp. $210{ }^{\circ} \mathrm{C}$. IR (KBr) $\left(v_{\max }, \mathrm{cm}^{-1}\right): 3228,1566,1525,1444 .{ }^{1} \mathrm{H}$ NMR(DMSO$d 6,100 \mathrm{MHz}): \delta=2.12$ (s, 3H, Me), 3.65 (s, 3H, -OMe), 5.92 (s, 1H, CH), 7.06-8.02 (m, $10 \mathrm{H}, \mathrm{ArH}), 11.30(\mathrm{~s}, 1 \mathrm{H}, \mathrm{NH})$. Mass $\mathrm{m} / \mathrm{z}: 342(\mathrm{M}+)$. Anal. Calcd for $\mathrm{C}_{22} \mathrm{H}_{18} \mathrm{~N}_{2} \mathrm{O}_{2}: \mathrm{C}$ 77.17, H 5.30, N 8.18, Found: C 76.02, H 5.22, N 8.55.

(Entry 5): mp. $275^{\circ} \mathrm{C}$. IR (KBr) $\left(v_{\max }, \mathrm{cm}^{-1}\right)$ : 3424, 1555, 1512, 1404. ${ }^{1} \mathrm{H}$ NMR(DMSOd6, 100MHz): $\delta=2.10$ (s, 3H, Me), 5.91 (s, 1H, CH), 7.10-8.30 (m, 13H, ArH), 11.10 (s, $1 \mathrm{H}, \mathrm{NH})$. Mass $\mathrm{m} / \mathrm{z}$ : $362(\mathrm{M}+)$. Anal. Calcd for $\mathrm{C}_{25} \mathrm{H}_{18} \mathrm{~N}_{2} \mathrm{O}$ : C 82.85, H 5.01, N 7.73, Found: C 81.17, H 5.21, N 7.57.

(Entry 9): mp. $233^{\circ} \mathrm{C}$. IR (KBr) $\left(v_{\max }, \mathrm{cm}^{-1}\right):{ }^{1} \mathrm{H}$ NMR (DMSO-d6, 100MHz): $\delta=2.07$ (s, 3H, Me), 5.97 (s, 1H, CH), 7.20-7.92 (m, 10H, ArH), 10.45 (br, 1H, NH). Mass m/z: 346 $(\mathrm{M}+)$. Anal.Calcd for $\mathrm{C}_{21} \mathrm{H}_{15} \mathrm{ClN}_{2} \mathrm{O}$ : C 72.73, H 4.36, N 8.08, Found: C 72.08, H 4.58, N, 7.86.

\section{Results and Discussion}

The catalytic efficiency of $\mathrm{Sc}(\mathrm{OTf})_{3}, \mathrm{Yb}(\mathrm{OTf})_{3}, \mathrm{La}(\mathrm{OTf})_{3}, \mathrm{Zn}(\mathrm{OTf})_{2}$ and $\mathrm{Cu}(\mathrm{OTf})_{2}$ was studied. In all cases $10 \mathrm{~mol} \%$ of the catalyst was used and the reaction was carried out under solvent free condition. As shown in the Table 1, the best result was obtained when copper(II) triflate was used as a catalyst. Therefore, the further study were carried out using copper(II) triflate as the best catalyst among the used catalyst.

To find the optimum reaction temperature, the synthesis of compound 2 (Table 2, entry 2) was studied in the presence of $10 \mathrm{~mol} \%$ copper(II) triflate at the different temperatures of $25,45,65,80$ and 100 . The results reveal that the reaction at $80{ }^{\circ} \mathrm{C}$ proceeded in the highest yield among the five tested temperatures. Therefore, $80{ }^{\circ} \mathrm{C}$ was chosen for the synthesis of different derivatives.

Having optimized the reaction temperature, a range of benzochromeno-pyrazoles was examined to explore the generality of this reaction and the results are illustrated in Table 2. Several aromatic aldehydes bearing different substituents were employed in the reaction. 
The methodology can be applied to aromatic aldehydes either with electronwithdrawing groups (such as nitro group, halogen) or electron-donating groups (such as methoxy group) with moderate to excellent yields. However, when the aliphatic aldehyde was applied to this reaction, no expected product was obtained.

Table 1. Benzochromeno-pyrazoles synthesis catalyzed by metal triflates under solvent free condition at $80{ }^{\circ} \mathrm{C}$

\begin{tabular}{cccc} 
& \\
\hline Entry & Catalyst & Time, h & Yield, \% \\
\hline 1 & $\mathrm{Sc}(\mathrm{OTf})_{3}$ & 7 & 76 \\
\hline 1 & $\mathrm{Yb}(\mathrm{OTf})_{3}$ & 8 & 65 \\
2 & $\mathrm{La}(\mathrm{OTf})_{3}$ & 8.5 & 88 \\
3 & $\mathrm{Zn}(\mathrm{OTf})_{2}$ & 6 & 92 \\
4 & $\mathrm{Cu}(\mathrm{Otf})_{2}$ & 6 & $\begin{array}{c}\text { Solvent-free } \\
\text { conditions }\end{array}$ \\
\hline
\end{tabular}

Table 2. Results of benzochromeno-pyrazole derivative synthesis using $\mathrm{Cu}(\mathrm{OTf})_{2}$ under solvent-free conditions

Entry

A plausible mechanism of the reaction was presented in Scheme 2. As shown the mechanism may involves the initial nucleophilic addition of 3-methyl- $1 H$-pyrazol-5(4H)- 
one to the activated aromatic aldehyde, which may be catalyzed by $\mathrm{Cu}(\mathrm{OTf})_{2}$, to give $\mathbf{A}$, nucleophilic addition of $\alpha$-naphthol $/ \beta$-naphthol to the intermediate $\mathbf{A}$ and finally heterocyclization followed by dehydration.

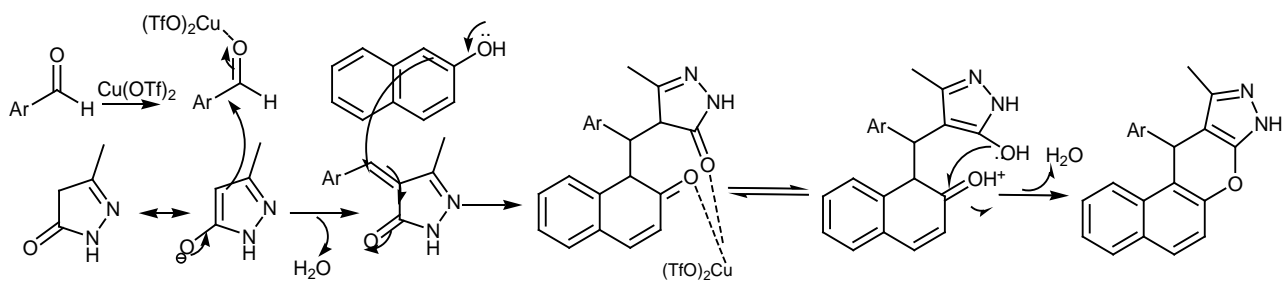

[A]

Scheme 2. The proposed mechanism for synthesis of benzochromeno-pyrazoles

\section{Conclusion}

In summary, metal triflates exhibited high efficiency for the synthesis of benzochromenopyrazole. An efficient, one-pot synthesis of benzochromeno-pyrazole derivatives from aromatic aldehydes, 3-methyl-1H-pyrazol-5(4H)-one and $\alpha$-or $\beta$-naphthol under solvent-free conditions catalyzed by copper(II) triflate has been described.

\section{References}

1. Ratnadeep S J, Priyanka G M, Shaikh M U, Rajesh R K and Gill G H, Chin Chem Lett., 2010, 21, 429.

2. Hertweck C J, Prakt Chem., 2000, 342, 3.

3. Kobayashi S, Eur J Org Chem., 1999, 15.

4. Potdar M K, Mohile S S and Salunkhe M M, Tetrahedron Lett., 2001, 42, 9285.

5. Anderson D R, Hegde S, Reinhard E, Gomez L, Vernier WF, Lee L, Liu S, Sambandam P A, Snider and Masih L, Bioorg Med Chem Lett., 2005, 15, 1587.

6. Abunada N M, Hassaneen H M, Samaha A M S A and Miqdad O A, J Braz Chem Soc., 2009, 20, 975.

7. Heravi, M M, Saeedi M, Beheshtiha Y and Oskooie H A, Mol Divers., 2010, DOI 10.1007/s11030-010-9263-4.

8. Zonouz A M and Sahranavard N, E-J Chem., 2010, 7(S1), S372-S376.

9. $\quad$ Lindstrom U M, Chem Rev., 2002, 102, 2751.

10. Wang Z X and Qin H L, Green Chem., 2004, 6, 90-92.

11. Yoshizawa K, Toyota, S and Toda F, Green Chem., 2002, 4, 68.

12. Eshghi H, Zohuri G.H, Damavandi S and Vakili M, Chin Chem Lett., 2010, 21, 1423.

13- Eshghi H, Zohuri G H and Damavandi S, Synth React Inorg Met Org Nano Met Chem., 2011, 41, 266. 